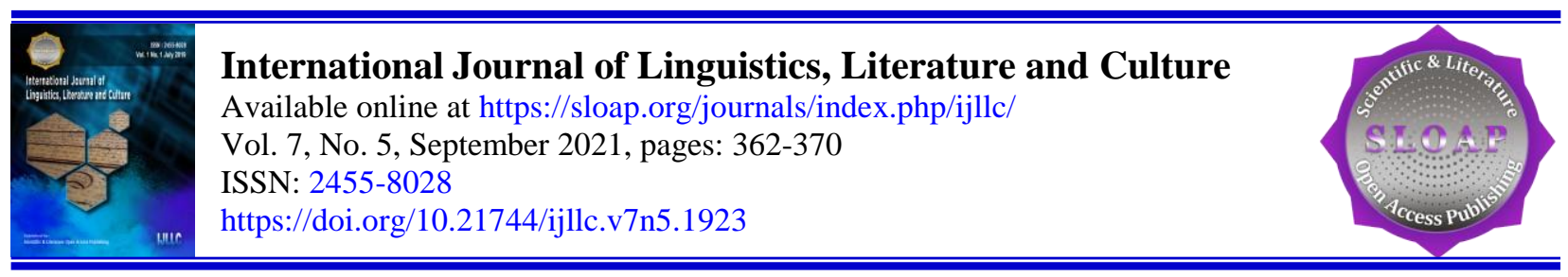

\title{
Collaborative Network Learning (CNL) on Students' Online Learning
}

Article history:

Submitted: 27 July 2021

Revised: 09 August 2021

Accepted: 18 Sept 2021

\section{Keywords:}

collaborative network learning;

English for food and beverage;

operation;

online learning;

students;

\begin{abstract}
This study aimed at enhancing students' online learning through CNL method in English for Food and Beverage Operation Subject Course. The participants of the study were 30 students at the second semester of Hospitality Study Program in State Polytechnic of Bali. Qualitative methods were used in data analysis; a sample of students' learning achievement was analyzed in light of the CNL assessment criteria. A questionnaire was administered to highlight progress in students' online learning in CNL method. CNL method proved to be effective in enhancing students' online learning in English for Food and Beverage Operation Subject Course, specifically in the online dialogue between co-learner, learner, and the teacher. Interviews with higher vocational education teachers of English emphasized students need for innovative online learning method such as CNL to help them develop as efficient learning. The online class encouraged students to work together as one team and to express their ideas fluently to excel in their learning assignments. Having an authentic reason for doing online learning motivated them to do research and to refine their learning assignments to be good enough to share with others.
\end{abstract}

International journal of linguistics, literature and culture () 2021. This is an open access article under the CC BY-NC-ND license (https://creativecommons.org/licenses/by-nc-nd/4.0/).

\section{Corresponding author:}

I Nyoman Kanca,

Politeknik Negeri Bali, Denpasar, Indonesia.

Email address: nyomankanca@pnb.ac.id

\footnotetext{
${ }^{a}$ Politeknik Negeri Bali, Denpasar, Indonesia

${ }^{\mathrm{b}}$ Politeknik Negeri Bali, Denpasar, Indonesia

${ }^{\mathrm{c}}$ Politeknik Negeri Bali, Denpasar, Indonesia
} 


\section{Introduction}

The 2019/2020 of even semester academic year in Tourism Department State Polytechnic of Bali has just ended and it prepares for beginning the odd semester of 2020/2021 academic year. However, new normal conditions of pandemic COVID-19 are not yet possible in full face-to-face learning. This condition might make learning still done online at the beginning of the new academic year although some green zone areas have been allowed to enter. Batlle \& Miller (2017), conducted a study about the perceptions of lecturers about CNL as a tool to observe peers in-service teachers in Spanish. Of course the momentum was welcomed and enthusiastic about students, teachers, parents, and educational stakeholders. The Freedom of Learning Policy provides space for students to learn anywhere, anytime, and with anyone. The learning process becomes more collaborative and holistic. Teachers also get convenience by preparing plans for implementing more meaningful learning. This policy strongly supports the implementation of learning when conditions in the Pandemics COVID-19 are still high. Teaching-learning process in this pandemic era is mostly conducted online as an effort to prevent the disease outbreaks. Similar to offline learning online learning requires a learning method to make the learning process run effectively and efficiently. Learning method is a method that refers to the way that will be used by educators to achieve the objectives of teaching and learning activities, to fit the expected goals. Therefore, every educator must master all knowledge of learning methods and find what types of learning methods they are capable of (Fadde \& Sullivan, 2013; Çelik et al., 2018; Ginaya, et al., 2018).

Learning method functions as an extrinsic motivation tool in which a good learning method must certainly be able to motivate students to be enthusiastic about learning (Wamnebo et al., 2018). In addition, learning method can be used as a learning strategy in order to respond to differences in absorptive capacity that exist in one class (Seidel et al, 2018; Kleinknecht \& Schneider, 2013; Gaudin \& Chaliès, 2015). By applying appropriate learning methods, students can absorb the knowledge delivered by educators well. In this case, the function of a teacher in the class as a facilitator that have the aim to deliver learning materials so that they are well absorbed by students. This can be said that the learning method is a tool to achieve learning objectives (Harmini et al., 2019; Arshavskaya \& Whitney, 2014). Problems that are often experienced in the educational process usually, a teacher's mistake in delivering subject matter with a boring method. Teachers should use methods that make students active in the learning process, such as active, innovative, creative, effective, Fun and Weighted learning. The term of active learning, which is intended in the learning process as teachers must be able to create an atmosphere in such a way that students actively ask, question, and express ideas. Other terms of innovative is intended so that teachers always package heterogeneous learning activities so that they have added value in providing learning services to students (Patarakin \& Shilova, 2015; Bonomi et al., 2020).

Creative is intended so that teachers are able to create heterogeneous learning activities so that they have added value in providing learning services to students. Effectively intended that the teacher is able to use the time to achieve the expected goals (Wang et al., 2016). Learning produces new experiences that tend to be permanent. Fun is intended so that the teacher is able to create a pleasant atmosphere of learning so that students focus fully (Lee, 2016). Fun and weighted are intended so that teachers create a fun learning atmosphere so that students are able to learn by enjoying in turn students are able to absorb the lesson as well as weighting so that the teacher in providing learning to students has good quality in order to achieve the learning objectives (Oliver \& Stallings, 2014). All college components become more collaborative and support each other. The hope, this condition can be disseminated to all colleges in remote parts of the country. Freedom of learning or Merdeka learns to provide space for the formation of an integrated educational ecosystem. The implementation of the Free Learning Policy makes the learning process more giving rights to students to grow and develop according to their needs and times. In this case, Covid must not depress students' spirit to achieve collaboration by all parties. The implementation of learning in educational units that are carried out online or offline requires the support of all parties. This support will be a supporting factor for learning success (Moore et al., 2011; Song et al., 2004).

The parties who support the learning process include parents, teachers, the college managements, education offices, the mass media, and others. The role of each party will contribute to its implementation. For example, parents who allow their children to carry out direct learning will be encouragement and examples for others, including the role of parents in assisting the implementation of online learning. The Ministry of Education and Culture has issued several online learning facilities, both in the form of online materials, development of online education content, collaboration with television, cooperation with providers, and others. Collaborative Networked Learning (CNL) learning that occurs through electronic dialogue between co-learners, leaners (students), and experts who each take control of themselves (Ellis et al., 2015). Students have a common goal, depend on each other and are

Kanca, I. N., Ginaya, G., \& Sri Astuti, N. N. (2021). Collaborative network learning (CNL) on students' online learning. International Journal of Linguistics, Literature and Culture, 7(5), 362-370. https://doi.org/10.21744/ijllc.v7n5.1923 
accountable to each other for their success. Collaborative Networked Learning (CNL) is that learning which occurs via electronic dialogue between self-directed co-learners and learners and experts. Learners share a common purpose, depend upon each other and are accountable to each other for their success. CNL occurs in interactive groups in which participants actively communicate and negotiation meaning with one another within a contextual framework which may be facilitated by an online coach, mentor or group leader (Jossberger et al., 2010). Therefore, the network environment can help the participants in extending and developing their capabilities and understanding in ways that are meet their aspirations. Networked learning is related to theories of distributed cognition and is rising with the emergence of 4.0 technologies (Wolters \& Taylor, 2012).

These conditions of disruption era require cooperation with all parties. In regards with the condition and development of the COVID-19 pandemic, it takes an integrative effort to support and realize students to continue to excel. Challenges faced by students, including: the reality conditions of students who still have limitations to do online learning both in terms of networks, devices, to motivation. For example, students in urban areas get internet access easier and faster, compared to students in areas with difficult networks. Additionally, a flexible policy of teachers is required for students who is encountering learning adversity due to the pandemic of COVID-19. This situation, certainly, has made them some limitations, especially in the sense of financial problems as many parents loss of jobs and some are in the status of unpaid live from the company where they work (Hatip, 2020; Khalil et al, 2020). The research conducted in this paper is based on Vygotsky's theory which states that collaborative learning is a cognitive development that depends on full social interaction which leads onto online learning communities that include interactivity, social context, and technologies. Additionally, this research relies on the community of inquiry framework for defining the CNL method (Ogle et al., 2017; McCrickerd et al., 2015).

\section{Methodology}

This research was conducted by applying a descriptive qualitative method. The sources and types of data are including both primary and secondary data. The primary data was obtained directly in the field through participant observation to two different classes of Travel and Tourism Study Program and one class of Business Management Study Program Tourism Department, Bali State Polytechnic and interview techniques. Whereas, the secondary data was collected through literature review technique. The three classes were selected based on purposive sampling technique where the researcher taught in the classes. The additional information to complete the data which is considered still insufficient was done by using a snowball sampling technique as one of the nonprobability sampling techniques in qualitative research by doing a tracer study. The tracer study was done for the purpose of looking for graduates as key informants in field research that helps researchers find other key informants or open access to respondents to be studied. This sampling technique is applied for the purpose of examining those which are related to the implementation of CNL model in designing learning materials in the context of tourism both services' and hospitalities' industries. The data, subsequently, were analyzed with qualitative descriptive methods based on an inductive methodological paradigm that departs from specific to general principles. Additionally, by applying a descriptive analysis method, the data that has been collected in the form of implementing CNL by describing information obtained from triangulation data collection provided by stakeholders, namely by comparing data obtained from interviews with the stakeholders, observations made by researchers and documents related to the problem. So that later the results obtained can be tested for validity and can be described or explained in the discussion. The results of the study are presented in formal and informal methods (Krismayani et al., 2020; Ginaya et al., 2018).

\section{Results and Discussions}

This study concerns with analyzing the qualitative data from the answer to the research question from the whole observation, in-depth interview, and literature review of problem solving on student's online learning through CNL method for Food and Beverage Subject Course in vocational education. The research questions in this study were concerned about how CNL method is able to motivate the students of the Tourism Department, Bali State Polytechnic in mastering English. This method of learning can be as an opportunity for enhancing the graduates' quality competence. Additionally, all the potential teaching and learning skills possessed by teachers and students in this digital era require to be developed as an endeavor to pursue the process of gaining experience, social interaction 
and communication, and group collaboration as professional competencies. The endeavor requires a distinctive policy of vocational education in this industry 4.0 era in order for the graduates as the learning output to be competitive in the workforce. All of the aforementioned issues are discussed in this part.

The teaching-learning process in vocational colleges such as the Bali State Polytechnic seeks to make students master the elements of competence in accordance with the performance demanded by the industry. This requires integrated learning between related courses when referring to the application of a curriculum based on national qualification frameworks or KKNI. Currently, the study in the Tourism Department consisting of three courses, namely Tourism and Travel, Hotel, and Tourism Business Management Study Programs has adopted the KKNI based curriculum. However, the results of a search study with observations and interviews to the lecturers in three study programs, Bali State Polytechnic show that English language study for college students is not optimal and integrated with other subjects, such as the course of Tour Guiding Technique, Front Office, Food and Beverage Service, and Organizing Events This is due to the lack of supporting factors, such as learning models, teaching books, learning time, and student motivation. Based on the results of observations and interviews to the management of majors and lecturers in the Tourism Department, there are several obstacles to integrating English courses with other courses, among which are:

1) Learning models that applied during this time are conducted in their respective classes or in the laboratory without involving two distinct teaching lecturers.

2) A teaching book that still uses text-based learning models.

3) Students are still less motivated to learn.

4) The perception of the students that were interviewed about english learning today also stated that english language learning needs to be integrated with the core subject of each program studies using communication in english.

A total of $95 \%$ of students said learning English courses should be integrated with core courses so that learning becomes more contextual.

\section{How to inspire students for collaborative learning in CNL method}

The role of college management, education offices and companies is very supportive to provide solutions. Some regions have asked for providers to provide network and access. Student achievement continues to be improved from the implementation of online model competitions, fostering students with online models, and developing talents through webinars. The National Achievement Center continues to conduct multi-strategy implementation of the competition and the development of talents, so as to produce a comprehensive profile or (digital cv). Students are increasingly motivated by the number of online-based activities to increase national achievement. Improving the achievement of students must be made efforts to accelerate, creativity, and innovation, so that renewal and enthusiasm for achievement continues to be buoyed even from home. With this condition there is still good academic and nonacademic achievement. Co-extracurricular activities strongly support the achievement of learning outcomes. Student achievement database in Indonesia starting from the preschool level, elementary, secondary, and higher education has the potential and has many awards at national and international activities.

Achievement data must be stored in a good data base and be a proof of accountability to the public for student achievement. This data is very important and strategic, so that it can be developed and used for policy makers, as well as collaborative needs for career development, achievement pathways, the future skills, and other ongoing programs. At the tertiary level, there are around 8 million students, their potential and development must be developed. The results of their achievements and development are documented in a data base, so that the data is ready to be published or exposed, so users will easily get it. The Merdeka Campus policy makes it more diverse and rich in each other's experiences. This diversity requires a complete data base. The Merdeka Campus Policy strongly encourages the sharing of resources and enrichment of various experiences outside the campus. Achievement database makes achievements that can be traced, fostered, development more directed, and the need for students to follow the development of achievements to the International level becomes easier. Development of student achievement is a very proud result.

Based on these achievements, the college must develop the students in accordance with the achievements. Nurturing the talents of students, both for the development of achievement and education. For students in basic

Kanca, I. N., Ginaya, G., \& Sri Astuti, N. N. (2021). Collaborative network learning (CNL) on students' online learning. International Journal of Linguistics, Literature and Culture, 7(5), 362-370. https://doi.org/10.21744/ijllc.v7n5.1923 
education, of course, the hope is to be able to get an award to continue to the secondary level in accordance with their achievements, and continue until the tertiary level of higher education. The development of student achievement talent is carried out intensively and involves all relevant stakeholders. The development process is also supported by the creation of creativity, innovation, and a leap of change. The college has to get out of the routine and develop dynamically according to the era. Student achievement improvement activities must be carried out holistically and collaboratively. Every educational stakeholders should support and succeed the National Achievement Center's activities towards superior and competitive graduates.

\section{Designing CNL method for food and beverage subject course}

In designing the CNL method for the classroom Food and Beverage Subject Course it is best to consider Charles Findley' model as a framework for designing the classroom of the future for the knowledge worker. In this case the students act such a role as workers need to engage in activities that allow them to approach problems from different vantage points, testing out assumptions, and redefining meanings, i.e. creative thinking in order to develop new viewpoints. Workers need to engage in the social, collaborative exchange of ideas in order to pose hypothetical problems, general hypotheses, conduct experiments and reflect on outcomes. Basically, workers are learning in groups to make meaning out of information. Not only do workers need to make meaning out of the information but in order to actually perform their jobs they need to be able to share that meaning with others as it is shown in Figure 1.

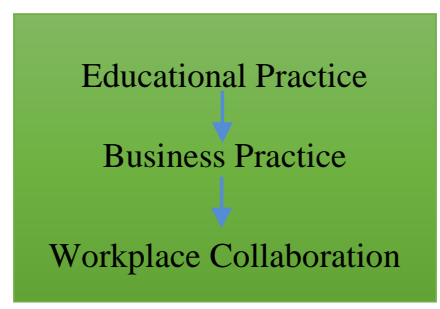

Figure 1. CNL's Model

Firstly, CNL is a method of learning in which both teacher and learners work collaboratively. The role of the teacher is a facilitator to enhance learning, on the other hand, learners manage to do the learning activities assigned to them. At the time learners perform their productive skills in using English the teacher can give feedback for the fluency and accuracy. Fluency can be first before the accuracy for the sake of motivating the learners to keep going using their English for communication. The teacher, in this case, is always to be reminded that the language learning is not talking about the language, but how to use the language for communication.

Secondly, CNL is encouraging a contextual learning in which the learning situation is conditioned for link and match between theory in the campus and the industry as a user of the graduates. The term link and match is well known in the world of education. In simple terms, link and match is a concept to align education with the needs of the business world. In this case, link and match usually relates to the readiness of vocational graduates like Polytechnic with industrial needs. During the learners studying in the campus, a collaborative team work can be created with the industry through oriented tasks where the learners will go to a company such as restaurants and bars to survey the working atmosphere of the food and beverage operation. In the class, then, the learners can share information with one another in order to complete learning assignment given by the teacher. This learning method can be done in a small group of four or five.

Thirdly, CNL is able to create learning network by sharing information using social media flat form, such as Facebook, WhatsApp group, Twitter. Social networks such as Facebook, Twitter and YouTube, and WhatsApp have quickly become a part of everyday life nowadays. One of the statements why social media is so famous is because the user uses it to interact on the internet network. Teachers / lecturers, students and students, graduates who have work in the industry as loyal users of social media. Therefore, graduates who work in the industry can share their experiences of their workplace for the teacher and learners in campus. Some samples of learning activities in CNL model can be seen below: 
1) Model 1. The Farmer's Problem

A farmer went to the market and bought a dog, a goat, and some vegetables. On his way home, he had to cross a river, but there was no bridge. So he had to take his purchases across the river in a small canoe. This canoe was so small that he could only take one of his purchases with him. First, he wanted to take the vegetables, but the dog and the goat began to fight. Then, he tried to take the dog, but the goat began to eat the vegetables. So, he took the goat first. This was alright because the dog would not eat the vegetables. But, what did the farmer do next?

2) Model 2. The Family Holidays

This is the last day for a family who spends their holiday in Bali before they go back to their country. They don't want to be separated from each other. Make a tour itinerary that suits all their needs. Doris (90 years old): She wants to visit Besakih Temple ( $75 \mathrm{Km}$ from the hotel) David (20 years old): He wants to stay in a hotel for swimming and sunbathing on the beach. He hates shopping.

Model 1 is the first CNL that is good for motivating students in doing a collaborative learning, especially to attract their learning interests for solving the problem given. In addition, they can also practice using simple past tense and some vocabulary. The students can work in a small group to find a solution for the farmer problem. Various answers may arise, but it doesn't matter whether they are correct or not the most important thing is that they try to express their ideas and they are able to practice their English (Hu et al., 2014; Bates \& Khasawneh, 2007). Finally, one group of the students can give the best solution or if no one can give the best solution, the teacher can give the solution. This activity can be followed up by inviting the students if they can make other similar problems to be solved. The second model is a more complicated problem for the students to find their solution that can be done in a collaborative learning through CNL model. They also can work in a small group and similar to the first model various answers are accepted and they can be ranked which one is the best answer. While the third model is the most difficult one where the students in turn to be judges and chefs. Starting from the judges they should be able to give three ingredients to the chefs for making a recipe and the chefs will be able to create a recipe and name it based on the three main ingredients given and other basic ingredients. At last, the judges will decide which recipe is the best. In more real practice, the students can video this problem solving activity so that beside they practice English as a foreign language the core competency of food and beverage operation, they also can practice the media and ICT literacy skill in making video by utilizing their smartphones starting from shooting, editing, until the video is uploaded to social media like YouTube and they can share the link to be viewed and subscribed (Jensen et al., 1996; Wiendahl et al., 2007).

\section{Conclusion}

The 4.0 education Era, the role of the teacher in vocational education is important and Strategic. In this era, a teacher must be able to develop learning methods that adapt to the needs of the learners and adapt to the advancement of technology. In order to produce graduates who have high competitiveness and are ready to compete need a teacher who has a core competency of science (core competence) strong, has soft skills, critical thinking, creative, communicative and able to collaborate well with students. Teachers should be able to adapt to contemporary developments. Learning methods applied can no longer apply conventional ones, teachers must be able to follow the development of technology so as to produce highly competitive graduates. Teachers also play a role to spread passion and inspire students, teachers also become friends for students, and teachers also have to model and character. One of the keys to facing future challenges is innovation creation. The development of crystalline and creative thinking skills and solving problems related to the lives of learners is important. This realization needs to be a foothold in promoting contextual learning. Therefore, teachers need to do, seriously designing the learning based on the premise of the learning process. More innovative demands in the learning process and hope for the development of sharp thinking in relation to the quality of graduates. If the teacher is still using conventional teaching methods, the curriculum is as good as not being able to form qualified graduates.

Kanca, I. N., Ginaya, G., \& Sri Astuti, N. N. (2021). Collaborative network learning (CNL) on students' online learning. International Journal of Linguistics, Literature and Culture, 7(5), 362-370. 
Conflict of interest statement

The authors declared that they have no competing interest.

Statement of authorship

The authors have a responsibility for the conception and design of the study. The authors have approved the final article.

\section{Acknowledgments}

The authors are very grateful to some parties who have given contributions and encouragements in completing this article. Particular thanks are owed to Kementerian Pendidikan, Kebudayaan, Riset, dan Teknologi of Republic Indonesia who funded the authors' research in the scheme of DRPM-PTUPT year 3. 


\section{References}

Arshavskaya, E., \& Whitney, A. E. (2014). Promoting pre-service second language (L2) teacher learning via narrative: A sociocultural perspective. Journal of Language Teaching and Research, 5(4), 731.

Bates, R., \& Khasawneh, S. (2007). Self-efficacy and college students' perceptions and use of online learning systems. Computers in Human Behavior, 23(1), 175-191. https://doi.org/10.1016/j.chb.2004.04.004

Batlle, J., \& Miller, P. (2017). Video enhanced observation and teacher development: Teachers' beliefs as technology users. EDULEARN17 Proceedings, 1.

Bonomi, S., Sarti, D., \& Torre, T. (2020). Creating a collaborative network for welfare services in public sector. A knowledge-based perspective. Journal of Business Research, 112, 440-449. https://doi.org/10.1016/j.jbusres.2019.11.050

Çelik, S., Baran, E., \& Sert, O. (2018). The affordances of mobile-app supported teacher observations for peer feedback. International Journal of Mobile and Blended Learning (IJMBL), 10(2), 36-49.

Ellis, J., McFadden, J., Anwar, T., \& Roehrig, G. (2015). Investigating the social interactions of beginning teachers using a video annotation tool. Contemporary Issues in Technology and Teacher Education, 15(3), 404-421.

Fadde, P., \& Sullivan, P. (2013). Using interactive video to develop pre-service teachers' classroom awareness. Contemporary Issues in Technology and Teacher Education, 13(2), 156-174.

Gaudin, C., \& Chaliès, S. (2015). Video viewing in teacher education and professional development: A literature review. Educational research review, 16, 41-67.

Ginaya, G., Rejeki, I. N. M., \& Astuti, N. N. S. (2018). The effects of blended learning to students' speaking ability. International journal of linguistics, literature and culture, 4(3), 1-14.

Ginaya, G., Rejeki, I. N. M., \& Astuti, N. N. S. (2018). The effects of blended learning to students' speaking ability: A study of utilizing technology to strengthen the conventional instruction. International Journal of Linguistics, Literature and Culture, 4(3), 1-14. Retrieved from https://sloap.org/journals/index.php/ijllc/article/view/158

Harmini, A. A. A. N., Ginaya, G., Widhari, C. I. S., \& Pemayun, I. D. G. A. (2019, October). Motivation and SelfEfficacy of Travel and Tourism Business Study Program Using English to Support The Graduate Competence. In International Conference On Applied Science and Technology 2019-Social Sciences Track (iCASTSS 2019) (pp. 66-71). Atlantis Press.

Hatip, A. (2020). The Transformation Of Learning During Covid-19 Pandemic Towards The New Normal Era. PROCEEDING UMSURABAYA.

Hu, Y. H., Lo, C. L., \& Shih, S. P. (2014). Developing early warning systems to predict students' online learning performance. Computers in Human Behavior, 36, 469-478. https://doi.org/10.1016/j.chb.2014.04.002

Jensen, P. S., Martin, D., \& Watanabe, H. (1996). Children's response to parental separation during Operation Desert Storm. Journal of the American Academy of Child \& Adolescent Psychiatry, 35(4), 433-441. https://doi.org/10.1097/00004583-199604000-00009

Jossberger, H., Brand-Gruwel, S., Boshuizen, H., \& Van de Wiel, M. (2010). The challenge of self-directed and self-regulated learning in vocational education: A theoretical analysis and synthesis of requirements. Journal of vocational education and training, 62(4), 415-440.

Khalil, M., Pirpamer, L., Hofer, E., Voortman, M. M., Barro, C., Leppert, D., ... \& Kuhle, J. (2020). Serum neurofilament light levels in normal aging and their association with morphologic brain changes. Nature communications, 11(1), 1-9.

Kleinknecht, M., \& Schneider, J. (2013). What do teachers think and feel when analyzing videos of themselves and other teachers teaching?. Teaching and teacher education, 33, 13-23.

Krismayani, N. W., Suastra, I. M., Suparwa, I. N., \& Sudipa, I. N. (2020). The english material needs of economics and business students. International Journal of Linguistics, Literature and Culture,6(1), 51-61. https://doi.org/10.21744/ijllc.v6n1.829

McCrickerd, K., Lensing, N., \& Yeomans, M. R. (2015). The impact of food and beverage characteristics on expectations of satiation, satiety and thirst. Food quality and preference, 44, 130-138. https://doi.org/10.1016/j.foodqual.2015.04.003

Moore, J. L., Dickson-Deane, C., \& Galyen, K. (2011). e-Learning, online learning, and distance learning environments: Are they the same?.The Internet and higher education, 14(2), 129-135. https://doi.org/10.1016/j.iheduc.2010.10.001

Kanca, I. N., Ginaya, G., \& Sri Astuti, N. N. (2021). Collaborative network learning (CNL) on students' online learning. International Journal of Linguistics, Literature and Culture, 7(5), 362-370. https://doi.org/10.21744/ijllc.v7n5.1923 
Ogle, A. D., Graham, D. J., Lucas-Thompson, R. G., \& Roberto, C. A. (2017). Influence of cartoon media characters on children's attention to and preference for food and beverage products. Journal of the Academy of Nutrition and Dietetics, 117(2), 265-270. https://doi.org/10.1016/j.jand.2016.08.012

Oliver, K., \& Stallings, D. (2014). Preparing teachers for emerging blended learning environments. Journal of Technology and Teacher Education, 22(1), 57-81.

Patarakin, Y., \& Shilova, O. (2015). Concept of learning design for collaborative network activity. Procedia-Social and Behavioral Sciences, 214, 1083-1090. https://doi.org/10.1016/j.sbspro.2015.11.709

Seidel, J. A., Otsuka, A., \& Kabashima, K. (2018). Anti-PD-1 and anti-CTLA-4 therapies in cancer: mechanisms of action, efficacy, and limitations. Frontiers in oncology, 8, 86.

Song, L., Singleton, E. S., Hill, J. R., \& Koh, M. H. (2004). Improving online learning: Student perceptions of useful and challenging characteristics. The internet and higher education, 7(1), 59-70. https://doi.org/10.1016/j.iheduc.2003.11.003

Wamnebo, W., Hanapi, H., Bugis, R., \& Handayani, N. (2018). Students' Speaking Skill in Oral Descriptive Text by Using Video at Tenth Grade in SMA Negeri 1 Namlea. Jurnal Jupiter, 16(2), 98.

Wang, D., Cui, P., \& Zhu, W. (2016, August). Structural deep network embedding. In Proceedings of the 22nd ACM SIGKDD international conference on Knowledge discovery and data mining (pp. 1225-1234).

Wiendahl, H. P., ElMaraghy, H. A., Nyhuis, P., Zäh, M. F., Wiendahl, H. H., Duffie, N., \& Brieke, M. (2007). Changeable manufacturing-classification, design and operation. CIRP annals, 56(2), 783-809. https://doi.org/10.1016/j.cirp.2007.10.003

Wolters, C. A., \& Taylor, D. J. (2012). A self-regulated learning perspective on student engagement. In Handbook of research on student engagement (pp. 635-651). Springer, Boston, MA. 